\title{
Large-Scale Postmarketing Surveillance of Biological Drugs for Immune-Mediated Inflammatory Diseases Through an Italian Distributed Multi-Database Healthcare Network: The VALORE Project
}

\author{
Gianluca Trifirò ${ }^{1}$ - Valentina Isgrò̀ ${ }^{1}$. Ylenia Ingrasciotta ${ }^{2}$. Valentina lentile ${ }^{2}$ Luca L'Abbate $^{1} \cdot$ Saveria S. Foti $^{3}$. \\ Valeria Belleudi ${ }^{4}$. Francesca Poggi ${ }^{4}$ - Andrea Fontana ${ }^{5}$ - Ugo Moretti ${ }^{1} \cdot$ Riccardo Lora $^{1} \cdot$ Alberto Sabaini ${ }^{6}$. \\ Ilenia Senesi ${ }^{7}$. Carla Sorrentino ${ }^{8}$. Maria R. Puzo ${ }^{9} \cdot$ Angela Padula $^{10}$ - Mariano Fusco ${ }^{11}$ - Roberta Giordana ${ }^{12}$. \\ Valentina Solfrini ${ }^{13}$. Aurora Puccini ${ }^{13} \cdot$ Paola Rossi $^{14}$ - Stefania Del Zotto ${ }^{15}$. Olivia Leoni ${ }^{16}$. Martina Zanforlini ${ }^{17}$. \\ Domenica Ancona ${ }^{18}$. Vito Bavaro ${ }^{18}$. Donatella Garau ${ }^{19}$. Stefano Ledda ${ }^{20}$. Salvatore Scondotto ${ }^{21}$. \\ Alessandra Allotta ${ }^{21}$. Marco Tuccori ${ }^{22} \cdot$ Rosa Gini $^{23}$ - Giampaolo Bucaneve ${ }^{24}$. David Franchini ${ }^{25}$. Anna Cavazzana ${ }^{26}$. \\ Valeria Biasi ${ }^{26}$. Stefania Spila Alegiani ${ }^{27} \cdot$ Marco Massari $^{27} \cdot$ VALORE Project Collaborators
}

Accepted: 25 August 2021 / Published online: 12 October 2021

(c) The Author(s) 2021

\begin{abstract}
Background Biological drugs have improved the management of immune-mediated inflammatory diseases (IMIDs) despite being associated with important safety issues such as immunogenicity, infections, and malignancies in real-world settings. Objective The aim of this study was to explore the potential of a large Italian multi-database distributed network for use in the postmarketing surveillance of biological drugs, including biosimilars, in patients with IMID.

Methods A retrospective cohort study was conducted using 13 Italian regional claims databases during 2010-2019. A tailor-made R-based tool developed for distributed analysis of claims data using a study-specific common data model was customized for this study. We measured the yearly prevalence of biological drug users and the frequency of switches between originator and biosimilars for infliximab, etanercept, and adalimumab separately and stratified them by calendar year and region. We then calculated the cumulative number of users and person-years (PYs) of exposure to individual biological drugs approved for IMIDs. For a number of safety outcomes (e.g., severe acute respiratory syndrome coronavirus 2 [SARS-COV-2] infection), we conducted a sample power calculation to estimate the PYs of exposure required to investigate their association with individual biological drugs approved for IMIDs, considering different strengths of association.

Results From a total underlying population of almost 50 million inhabitants from 13 Italian regions, we identified 143,602 (0.3\%) biological drug users, with a cumulative exposure of 507,745 PYs during the entire follow-up. The mean age \pm standard deviation of biological drug users was $49.3 \pm 16.3$, with a female-to-male ratio of 1.2. The age-adjusted yearly prevalence of biological drug users increased threefold from 0.7 per 1000 in 2010 to 2.1 per 1000 in 2019. Overall, we identified 40,996 users of biosimilars of tumor necrosis factor (TNF)- $\alpha$ inhibitors (i.e., etanercept, adalimumab, and infliximab) in the years 2015-2019. Of these, $46 \%(N=18,845)$ switched at any time between originator and biosimilars or vice versa. To investigate a moderate association (incidence rate ratio 2) between biological drugs approved for IMIDs and safety events of interest, such as optic neuritis (lowest background incidence rate 10.4/100,000 PYs) or severe infection (highest background incidence rate 4312/100,000 PYs), a total of 43,311 PYs and 104 PYs of exposure to individual biological drugs, respectively, would be required. As such, using this network, of 15 individual biological drugs approved for IMIDs, the association with those adverse events could be investigated for four (27\%) and 14 (93\%), respectively.

Conclusion The VALORE project multi-database network has access to data on more than 140,000 biological drug users (and >0.5 million PYs) from 13 Italian regions during the years 2010-2019, which will be further expanded with the inclusion of data from other regions and more recent calendar years. Overall, the cumulated amount of person-time of exposure
\end{abstract}

The members of the VALORE Project Collaborators are mentioned in the Acknowledgments section.

Extended author information available on the last page of the article 
to biological drugs approved for IMIDs provides enough statistical power to investigate weak/moderate associations of almost all individual compounds and the most relevant safety outcomes. Moreover, this network may offer the opportunity to investigate the interchangeability of originator and biosimilars of several TNF $\alpha$ inhibitors in different therapeutic areas in real-world settings.

\section{Key Points}

The VALORE project multi-database network has access to data on more than 140,000 biological drug users with immune-mediated inflammatory diseases (with a cumulative exposure of 507,745 person-years during the entire follow-up) from 13 Italian regions.

Overall, the cumulated amount of person-time of exposure to biological drugs approved for immune-mediated inflammatory diseases provides enough statistical power to investigate weak, moderate, and strong associations of almost all individual biological drugs and the most clinically relevant safety outcomes.

This distributed database network captured data on a large number of etanercept, adalimumab, and infliximab users who switched between originator and biosimilar during the entire follow-up, thus offering the opportunity to investigate interchangeability in a real-world setting.

\section{Introduction}

Recent years have seen the introduction into the market of highly innovative biological drugs, leading to improved management of immune-mediated inflammatory diseases (IMIDs) in dermatologic, rheumatologic, and gastroenterological settings. Since 2006, in parallel, several widely prescribed biological drugs have lost their patents, opening the market to a growing number of biosimilars [1]. Biological drugs, including biosimilars, approved for IMID treatment may be associated with important safety issues that have been mostly detected in the postmarketing setting [2]. In particular, immunogenicity (e.g., hypersensitivity and infusion reactions), infections, malignancies, and other serious adverse reactions have been repeatedly documented for several biological drugs [3-5].

More recently, with the severe acute respiratory syndrome coronavirus-2 (SARS-CoV-2) causing the coronavirus disease 2019 (COVID-19) pandemic, there is uncertainty about the risk of SARS-COV-2 infection and COVID-19 prognosis in patients receiving chronic treatment with biological drugs interfering with the immune system [6, 7]. Specifically, clinicians have debated whether treatment with biological drugs should be interrupted to prevent severe complications of COVID-19, such as interstitial pneumonia $[8,9]$. The American College of Rheumatology recommends continuing treatment with biological drugs in patients with stable rheumatic diseases in the absence of COVID-19 or SARSCoV-2 exposure [10]. On the other hand, the repurposed use of several biological drugs (e.g., tocilizumab, sarilumab) has been proposed for patients with COVID-19 and is being investigated in a number of ongoing experimental studies [11-14].

Another important issue to be addressed in the postmarketing setting concerns the interchangeability of biological drug originators and biosimilars and, specifically, the presumed risk of immunogenicity by switching between biological drugs, which may cause a lack of effect and toxicity. Members of the Biosimilar Working Party of the European Medicines Agency, after exploring the available safety data on switching between a biosimilar and its reference product, concluded that biosimilars licensed in the EU are interchangeable. However, the safety of switching between originator and biosimilars requires additional investigation in real-life settings and can be further addressed by generating clinical evidence of biosimilarity from premarketing studies and intensified postmarketing surveillance $[15,16]$.

It is therefore imperative to set up large-scale real-world data infrastructure to generate real-world evidence on the comparative benefit-risk profiles of individual biological drugs (including biosimilars) in IMIDs, integrating evidence from pivotal clinical trials and rapidly investigating emerging safety issues, such as COVID-19.

In general, claims databases and clinical registries are sources of real-world data with both potential for and limitations in the monitoring of the benefit-risk profile of biological drugs. In some European countries, established registries of patients with IMID, such as the British Association of Dermatologists Biologic and Immunomodulators Register (BADBIR), the British Society of Rheumatology Biologics Registry (BSRBR), the Antirheumatic Therapies In Sweden (ARTIS), the Psoriasis Registry (PsoReg) in Sweden, and the Danish Registry for Biologic Therapies in Rheumatology (DANBIO) [17-19], have been used for post-authorization safety studies in the EU, but these sources lack power and length of follow-up. Likewise, the Biologics and Biosimilars Collective Intelligence Consortium (BBCIC) is a nonprofit research consortium that was established in the USA in 2015 to conduct observational studies on the safety and effectiveness of biological drugs, including biosimilars, using claims data [20]. 
Irrespective of the data source, monitoring of the appropriate prescribing and the benefit-risk profile of (newly marketed) biological drugs as well as of the interchangeability of originators and biosimilars calls for the implementation of large-scale real-world data networks for rapid, systematic, and comparative assessment of biological drugs in the postmarketing setting [21].

The Italian VALORE (Postmarketing evaluation of the benefit-risk profile of originator biological drugs vs. biosimilars in dermatology, rheumatology, gastroenterology and oncohematology through healthcare database network, active surveillance and clinical registries) project, funded by the Italian Medicines Agency, set up a distributed multidatabase network of claims databases linked to clinical registries from almost the entire country. The aim of this study was to demonstrate the enormous potential of the VALORE project network for conducting postmarketing surveillance of biological drugs, including biosimilars, in Italian patients with IMIDs.

\section{Methods}

This was a retrospective cohort multi-database study. Fully anonymized data were extracted from the claims databases of 13 Italian regions (Abruzzo, Apulia, Basilicata, Campania, Emilia-Romagna, Friuli Venezia Giulia, Lazio, Lombardy, Sardinia, Sicily, Tuscany, Umbria, and Veneto), which covers almost 50 million inhabitants $(83.3 \%$ of the Italian population).

\subsection{Data Sources}

In this study, the following regional claims databases were considered: (1) inhabitant registry, including demographic information about the date of birth, sex, and date of registration in the regional healthcare system; (2) drug dispensing from pharmacy claims database; and (3) birth registry (Fig. 1). Data about biological drugs were recorded using the anatomical therapeutic chemical (ATC) classification system and national drug code (NDC), and the defined daily dose (DDD) was used as the unit to estimate drug exposure [22].

Biological drugs with subcutaneous formulations are dispensed to patients by hospital pharmacists for outpatient use, whereas intravenous biological drugs (e.g., infliximab) are administered in dedicated hospital ambulatory care centers. In each region, information on dispensing of biological drugs, irrespective of the formulations, are collected in claims data.

In Italy, for each biological drug prescribed to outpatients, a therapeutic plan must be completed by a specialist physician employed by the national healthcare service. This therapeutic plan includes the drug name, dosing regimen, and indication for use. In five Italian regions (Apulia, Lazio, Friuli Venezia Giulia, Veneto, and Campania), electronic therapeutic plans can be linked at the individual level to the claims data sources.

\subsection{Study Population}

All people residing in the catchment areas of all participating regions between 1 January 2010 (or first available date) and 31 December 2019 (or last available date) were identified. Based on the data availability at the time of the study, Apulia and Campania (2014-2019), Sicily (2011-2018), Lazio (2010-2017), Basilicata (2017-2019), and Veneto (2015-2019) contributed fewer observation years. All subjects in the source population with at least one biological drug dispensing during the observation years were included in the study.

The date of the first biological drug dispensing (index drug) was used as the index date (ID). As a patient could potentially start multiple treatments with biological drugs during the entire study period, multiple individual biological drug-specific IDs per patient were considered, if appropriate.

Each patient was followed up from the ID until whichever of the following events occurred first: (1) patient's death, (2) transfer out of the database, or (3) end of the study period/ end of data collection of the database. The characteristics (total size, mean age, and sex distribution) of the underlying population of each region participating in the VALORE project network [23] are included in the electronic supplementary material (ESM)-1.

\subsection{Drugs of Interest}

Drugs of interest were biological drugs (originator and biosimilar) approved in Italy for IMIDs up to 31 December 2019: (1) tumor necrosis factor (TNF)- $\alpha$ inhibitors (i.e., infliximab, etanercept, adalimumab, golimumab, and certolizumab pegol), (2) interleukin inhibitors (i.e., anakinra, tocilizumab, secukinumab, ustekinumab, ixekizumab, brodalumab, sarilumab, guselkumab, tildrakizumab, risankizumab), and (3) selective immunosuppressants (i.e., abatacept, vedolizumab). Rituximab was not included in the analysis as it is mainly used in the onco-hematological setting. At the time of this study, the biosimilars of infliximab, etanercept, and adalimumab were available in the Italian market.

The ATC and NDC codes of the study drugs are included in ESM-2.

\subsection{Distributed Analyses}

A distributed analyses approach based on a "study-specific" common data model (CDM) strategy was used [24]. An R-based open-source tool "TheShinISS," developed by 


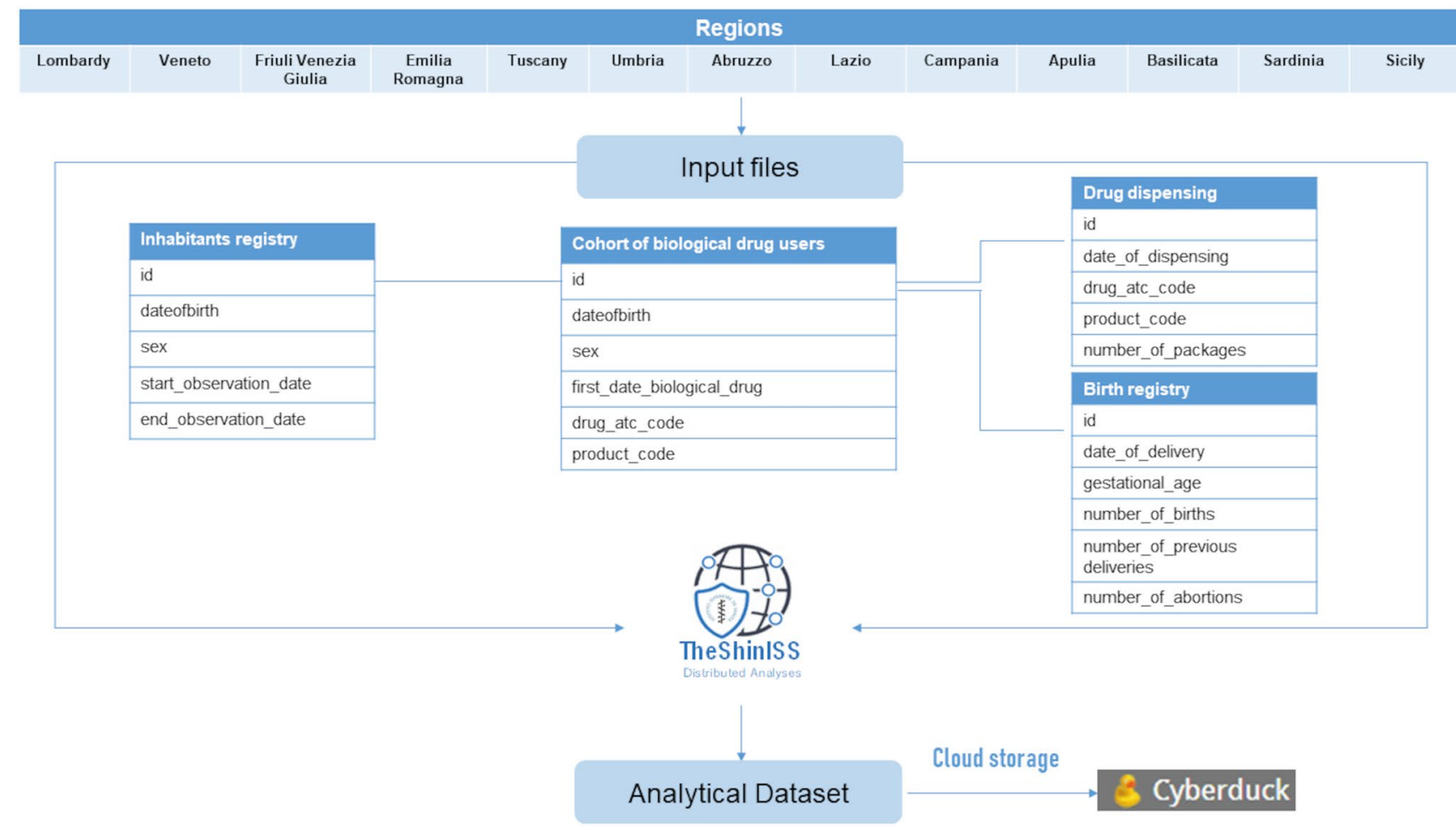

Fig. 1 VALORE project multi-database network using common data model. id index date, atc anatomical therapeutic chemical

the Italian National Institute of Health for conduction of distributed analyses and described elsewhere [14, 25-27], was customized for the purposes of the study. Specifically, it was delivered to regions for elaborating and processing, at the local level, data on a cohort of biological drug users approved for IMIDs, which were previously extracted and loaded into a study-specific CDM. This tool performs data quality control and ultimately generates an anonymized and harmonized analytic dataset to be shared for the centralized data analyses. A project-specific cloud storage browser, Cyberduck, was used for the latter purpose (Fig. 1).

\subsection{Analysis of Safety Outcomes}

We produced a list of the most relevant safety outcomes associated with the study drugs based on safety information reported in the summary of product characteristics (SmPCs) and the risk management plan (RMP). Specifically, all the safety outcomes reported in the "Important identified or potential risks" section of the RMPs and in paragraph 4.4 "Special warnings and precautions for use" of the SmPCs were collected. Safety outcomes from SmPCs and RMPs were grouped according to mechanistic classes of biological drugs (i.e., TNF $\alpha$ inhibitors, interleukin inhibitors, and selective immunosuppressants) and included in Table 1. Hierarchical attributions (i.e., important identified risk > important potential risk $>$ safety risk from SmPCs) were considered. Further identification of these safety outcomes, stratified by active substance, is provided in ESM 3-5.

To assess the potential of the multi-database network for the investigation of associations between clinically relevant safety outcomes and individual biological drugs approved for IMIDs, based on statistical power calculation, a sample of the previously mentioned adverse events with heterogenous background incidence rates (IRs) were selected: severe infections, SARS-CoV-2 infection, neoplasms, congestive heart failure, tuberculosis, and optic neuritis.

\subsection{Statistical Analysis}

Categorical variables of the study population were reported as absolute and relative frequencies (i.e., percentages). Continuous variables were reported as mean \pm standard deviation (SD).

Yearly prevalence of biological drug use was computed as the number of drug users over the total population for each calendar year, overall and stratified per region. Prevalence was adjusted for age categories $(<18,18-44,45-64$, $\geq 65$ years) using a standardized direct method based on the calendar year-specific Italian population. The yearly ageadjusted prevalence of biological drug users was graphically represented with a line chart for each region.

For each biological drug user, the number of days of therapy, based on the DDD and the amount of dispensed drug, 
was calculated for every year, and the average number of person-years (PYs) of exposure was computed in the study population. Cumulative time of exposure to biological drugs over the years was measured and stratified by region and molecule. The distribution of numbers and percentages of biological drug users (overall and within subgroups) were graphically described with bar plots or stacked bar plots as appropriate. Yearly cumulative numbers of biological drug users and PYs were graphically illustrated as stacked area plots.

The required amount of PYs of exposure to individual biological drugs, considering adverse events having various background IRs and different strengths of association, assessed using incident rate ratio (IRR), was graphically represented as approximate power curves [28].

The IRs of the safety outcomes in users of IMIDapproved biological drugs were retrieved from the literature [29-32]. The total amount of PYs of exposure that would be required to detect an association between any biological drugs approved for IMIDs and the events of interest was computed over varying magnitudes of IRR $(1.5,2,4$, and 6 ), using a one-sided significance level of $\alpha=0.05$ and a power of $80 \%(\beta=0.2)$, based on the formula described by Beaumont and Breslow [28]. Consequently, we determined the proportion of individual biological drugs among those included in the study for which data would be sufficient for the investigation of different safety outcomes. All statistical analyses were performed using R version 4.0 (The R Foundation for Statistical Computing, Vienna, Austria).

\section{Results}

From a total underlying population of almost 50 million inhabitants $(83.3 \%$ of the total Italian population; mean age range 42.1-47.1 years, female-to-male ratio [F/M ratio] 1.1; see ESM-1) from 13 Italian regions during the years 2010-2019, we identified 143,602 (0.3\%) biological drug users (mean \pm SD age $49.3 \pm 16.3, \mathrm{~F} / \mathrm{M}$ ratio of 1.2 ). The age-adjusted yearly prevalence of biological drug users increased threefold from 0.7 per 1000 inhabitants in 2010 to 2.1 per 1000 inhabitants in 2019 (Fig. 2). The Apulia and Umbria regions showed the highest prevalence of biological drug users (2.6 per 1000 inhabitants for both regions in 2019). Cumulative exposure was 507,745 PYs during the entire follow-up. On average, each user had 3.5 PYs of exposure (Fig. 3).

Looking at drug classes, the largest number of users was reported for TNF $\alpha$ inhibitors $(\mathrm{N}=118,276$ [82.4\%]; PYs 395,709 [77.9\%]), followed by interleukin inhibitors $(N=36,942$ [25.7\%]; 83,704 PYs [16.5\%]), and selective immunosuppressants $(N=16,918$ [11.8\%]; 25,300 PYs [5.0\%]). Regarding individual compounds, the largest number of users was observed for adalimumab $(N=61,748$ [43.0\%]; 121,363 PYs [23.9\%]), etanercept $(N=46,946$ [32.7\%]; 106,948 PYs [21.0\%]), and infliximab $(N=25,127$ [17.5\%]; 123,136 PYs [24.2\%]). Among interleukin inhibitors, the largest number of users was observed for ustekinumab $(N=12,648$ [8.8\% of total biological drug users]; 44,309 PYs [8.7\%]), followed by secukinumab $(N=12,564$ [8.7\%]; 14,467 PYs [2.8\%]). Sarilumab and brodalumab, which were introduced into the market at the end of the study period, showed the lowest cumulative number of users $(N=722[0.5 \%] ; 263$ PYs $[<0.1 \%] ;$ and $N=132[0.1 \%]$; 35 PYs $[<0.1 \%]$, respectively) (Fig. 4).

As regards specific age groups, 10,457 (7.3\%) biological drug users were aged $<18$ years and $46,479(32.4 \%)$ were aged $>65$ years. Among elderly patients, 8886 (6.2\% of total biological users) were aged $>80$ years (data not shown).

Overall, 40,996 users (almost 30\% of total users) of biosimilars of TNF $\alpha$ inhibitors (i.e., etanercept, adalimumab, and infliximab) were identified in the years 2015-2019 (Fig. 5D). The proportion of biosimilar users for these biological drugs increased in all the Italian regions over time (Fig. 5A-C). Of these, 46\% ( $N=18,845)$ of etanercept, adalimumab, and infliximab users switched between originator and biosimilars, or vice versa, at least once during the years 2015-2019.

As regards to safety outcomes, the IRs of some adverse events of interest in cohorts of biological drug users were identified from the literature [28-31] as reported here (from the highest to the lowest IR): 4312 for 100,000 PYs for severe infections; 382 for 100,000 PYs for neoplasms; 175 for 100,000 PYs for congestive heart failure; 164 for 100,000 PYs for SARS-CoV-2 infection; 95 for 100,000 PYs for tuberculosis; and 10.4 for 100,000 PYs for optic neuritis.

Figure 6 shows the amount of drug exposure in terms of PYs required to allow detection of a weak (IRR 1.5), moderate (IRR 2), strong (IRR 4), or very strong (IRR 6) association between an individual biological drug and each of the five adverse events of interest. In particular, for SARSCoV-2 infection, 12,439 PYs of exposure to any biological drug would be required to detect a weak association, which would allow investigation of nine of the 15 individual study drugs. For optic neuritis and severe infections (events with the lowest and highest background IR), 43,311 and 104 PYs of drug exposure would be necessary to detect a "moderate" association (i.e., IRR 2), which would allow investigation of, respectively, 4 and 14 of the 15 study drugs (Fig. 6).

Based on female biologic drug users with at least one delivery after ID, the number of pregnant women exposed to a biological drug in the VALORE project network was 794 
Table 1 Major safety outcomes for TNF $\alpha$ inhibitors, selective immunosuppressants, and interleukin inhibitors, as reported on the summaries of product characteristics and risk management plans

\begin{tabular}{|c|c|c|c|}
\hline Safety outcome & TNF-alpha inhibitors & $\begin{array}{c}\text { Selective } \\
\text { immunosuppressants }\end{array}$ & $\begin{array}{c}\text { Interleukin } \\
\text { inhibitors }\end{array}$ \\
\hline \multicolumn{4}{|l|}{ Immune system disorders } \\
\hline Hypersensitivity (incl. anaphylaxis or anaphylactoid reactions) ${ }^{\mathrm{a}, \mathrm{b}, \mathrm{c}}$ & $\cdot$ & $\cdot$ & $\cdot$ \\
\hline \multicolumn{4}{|l|}{ Infections and infestations } \\
\hline Tuberculosis a,b & - & $\cdot$ & - \\
\hline Sepsis ${ }^{\mathrm{a}, \mathrm{b}}$ & $\cdot$ & $\bullet$ & \\
\hline Pneumoniaa,b & $\cdot$ & $\cdot$ & \\
\hline Invasive fungal infection $\mathrm{s}^{\mathrm{a}, \mathrm{b}}$ & • & $\cdot$ & \\
\hline Hepatitis B virus (HBV) reactivation $\mathrm{a}^{\mathrm{a}, \mathrm{b}, \mathrm{c}}$ & - & • & - \\
\hline Gastrointestinal infections $^{c}$ & & $\cdot$ & \\
\hline Upper Respiratory Tract Infections $\mathrm{s}^{\mathrm{a}, \mathrm{b}}$ & & $\cdot$ & $\cdot$ \\
\hline Diverticulitis aggravated ${ }^{a, b}$ & & & • \\
\hline Conjunctivitis $^{\mathrm{a}, \mathrm{b}}$ & & & • \\
\hline Fungal infections ${ }^{a, b}$ & & & $\cdot$ \\
\hline \multicolumn{4}{|l|}{ Cardiac disorders } \\
\hline \multicolumn{4}{|l|}{ Congestive heart failure $\mathrm{a}^{\mathrm{a}, \mathrm{b}}$} \\
\hline Hyperlipidaemia $^{a}$ & & & $\bullet$ \\
\hline Major Adverse Cardiac Events (MACE) ${ }^{c}$ & & & $\cdot$ \\
\hline \multicolumn{4}{|l|}{ Gastrointestinal disorders } \\
\hline Inflammatory bowel disease (including Crohn's disease and ulcerative colitis) ${ }^{a, b, c}$ & & & $\cdot$ \\
\hline Gastrointestinal perforation ${ }^{\mathrm{b}}$ & & & $\cdot$ \\
\hline \multicolumn{4}{|l|}{ Hepatobiliary disorders } \\
\hline Worsening of hepatitis $\mathrm{C}^{\mathrm{a}}$ & • & & \\
\hline Autoimmune hepatitis ${ }^{\mathrm{a}}$ & $\cdot$ & & 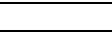 \\
\hline Acute liver failure $^{\mathrm{b}}$ & & & $\cdot$ \\
\hline Hepatitis $^{\mathrm{b}}$ & & & $\cdot$ \\
\hline Jaundice $^{\mathrm{a}}$ & & & $\bullet$ \\
\hline \multicolumn{4}{|l|}{ Respiratory, thoracic and mediastinal disorders } \\
\hline Eosinophilic pneumonia $^{a}$ & & & $\bullet$ \\
\hline Pulmonary alveolar proteinosis ${ }^{\mathrm{a}, \mathrm{c}}$ & & & $\cdot$ \\
\hline Pulmonary hypertension ${ }^{a, c}$ & 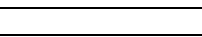 & & $\bullet$ \\
\hline Interstitial lung disease $\mathrm{e}^{\mathrm{a}, \mathrm{c}}$ & & & $\cdot$ \\
\hline \multicolumn{4}{|l|}{ Neoplasms benign, malignant and unspecified (incl. cysts and polyps) } \\
\hline Lymphomas $^{a, b, c}$ & $\cdot$ & & $\cdot$ \\
\hline Leukaemia $^{\mathrm{a}, \mathrm{b}}$ & $\cdot$ & & \\
\hline Melanoma $a^{a, b}$ & $\cdot$ & & \\
\hline Nonmelanoma skin cancer ${ }^{a, b, c}$ & - & - & $\cdot$ \\
\hline Merkel cell carcinoma $a^{\mathrm{a}, \mathrm{b}}$ & $\cdot$ & & \\
\hline Colon cancer/dysplasia ${ }^{\mathrm{a}, \mathrm{c}}$ & $\bullet$ & $\bullet$ & \\
\hline Lung cancer ${ }^{\mathrm{a}, \mathrm{c}}$ & $\cdot$ & & $\cdot$ \\
\hline Cervical cancer ${ }^{b}$ & $\cdot$ & & \\
\hline Breast cancer $^{\mathrm{a}}$ & $\bullet$ & & \\
\hline \multicolumn{4}{|l|}{ Blood and lymphatic system disorders } \\
\hline Pancytopenia, leukopenia, neutropenia and thrombocytopenia ${ }^{\mathrm{a}, \mathrm{b}}$ & $\cdot$ & & $\cdot$ \\
\hline Wegener's granulomatosis $^{\mathrm{a}}$ & $\bullet$ & & \\
\hline \multicolumn{4}{|l|}{ Musculoskeletal and connective tissue disorders } \\
\hline Lupus and lupus-like illness ${ }^{a, b}$ & $\cdot$ & & \\
\hline \multicolumn{4}{|l|}{ Nervous system disorders } \\
\hline Guillain-Barré syndrome $\mathrm{e}^{\mathrm{a}, \mathrm{b}}$ & $\cdot$ & & \\
\hline Multiple Sclerosis ${ }^{\mathrm{a}, \mathrm{b}}$ & $\cdot$ & & \\
\hline Serious depression (including suicidality) ${ }^{c}$ & $\cdot$ & & $\cdot$ \\
\hline Optic neuritis $^{\mathrm{b}}$ & $\cdot$ & & \\
\hline Progressive multifocal leukoencephalopathy (PML) ${ }^{\mathrm{a}, \mathrm{c}}$ & - & $\cdot$ & \\
\hline Reversible posterior leukoencephalopathy syndrome ${ }^{c}$ & $\bullet$ & & $\bullet$ \\
\hline Encephalitis/Leukoencephalomyelitis $^{c}$ & $\cdot$ & & \\
\hline Facial palsy & & & $\cdot$ \\
\hline \multicolumn{4}{|l|}{ Skin and subcutaneous tissue disorders } \\
\hline Exfoliative dermatitis $^{\mathrm{a}}$ & & & $\cdot$ \\
\hline Psoriasis $^{b}$ & & & $\cdot$ \\
\hline \multicolumn{4}{|l|}{ Immuno system disorders } \\
\hline Macrophage activation syndrome (MAS) ${ }^{\text {a }}$ & & & $\cdot$ \\
\hline Investigations & & & \\
\hline Transaminase elevations $^{\mathrm{a}}$ & & & $\cdot$ \\
\hline Increases in lipid parameters ${ }^{\mathrm{a}, \mathrm{c}}$ & & & $\cdot$ \\
\hline Vascular disorders & & & \\
\hline Venous thromboembolism ${ }^{c}$ & & & $\cdot$ \\
\hline Metabolism and nutrition disorders & & & \\
\hline Hypoglycaemia $^{a}$ & $\bullet$ & & \\
\hline Hyperlipidaemia $^{a}$ & & & $\bullet$ \\
\hline
\end{tabular}

$R M P$ risk management plan, $S m P C$ summary of product characteristics, $T N F$ tumor necrosis factor

${ }^{a}$ SmPC: paragraph 4.4, Special warnings and precautions for use

${ }^{\mathrm{b}} \mathrm{RMP}$ : Important identified risk (red shading)

${ }^{\mathrm{c}} \mathrm{RMP}$ : Important potential risk (blue shading) 
(data available from 11/13 regions). Considering the same sample size for the nonexposed group, the minimum statistically significant relative risk (RR) detectable by event rate is shown in Fig. 7. In particular, assuming an event rate of $7 \%$ for the outcome of interest, such as preterm delivery or low birth weight, it would be possible to detect associations with a RR of 1.45 .

\section{Discussion}

This is the first large-scale multi-database network (13 Italian regions covering an underlying population of almost 50 million inhabitants with 10 -year follow-up) to be specifically set up in Italy for postmarketing surveillance of biological drugs approved for IMIDs. Likewise, the BBCIC was established in the USA in 2015 to carry out observational studies of biological drugs using a distributed research network
Fig. 2 Age-adjusted yearly prevalence of use (per 1000 people) of biological drugs approved for immune-mediated inflammatory diseases, stratified by region in the period 2010-2019. Age adjustment was performed using standardized direct method, based on calendar year-specific Italian population for the following age categories: < 18, 18-44, 45-64, and $\geq 65$ years
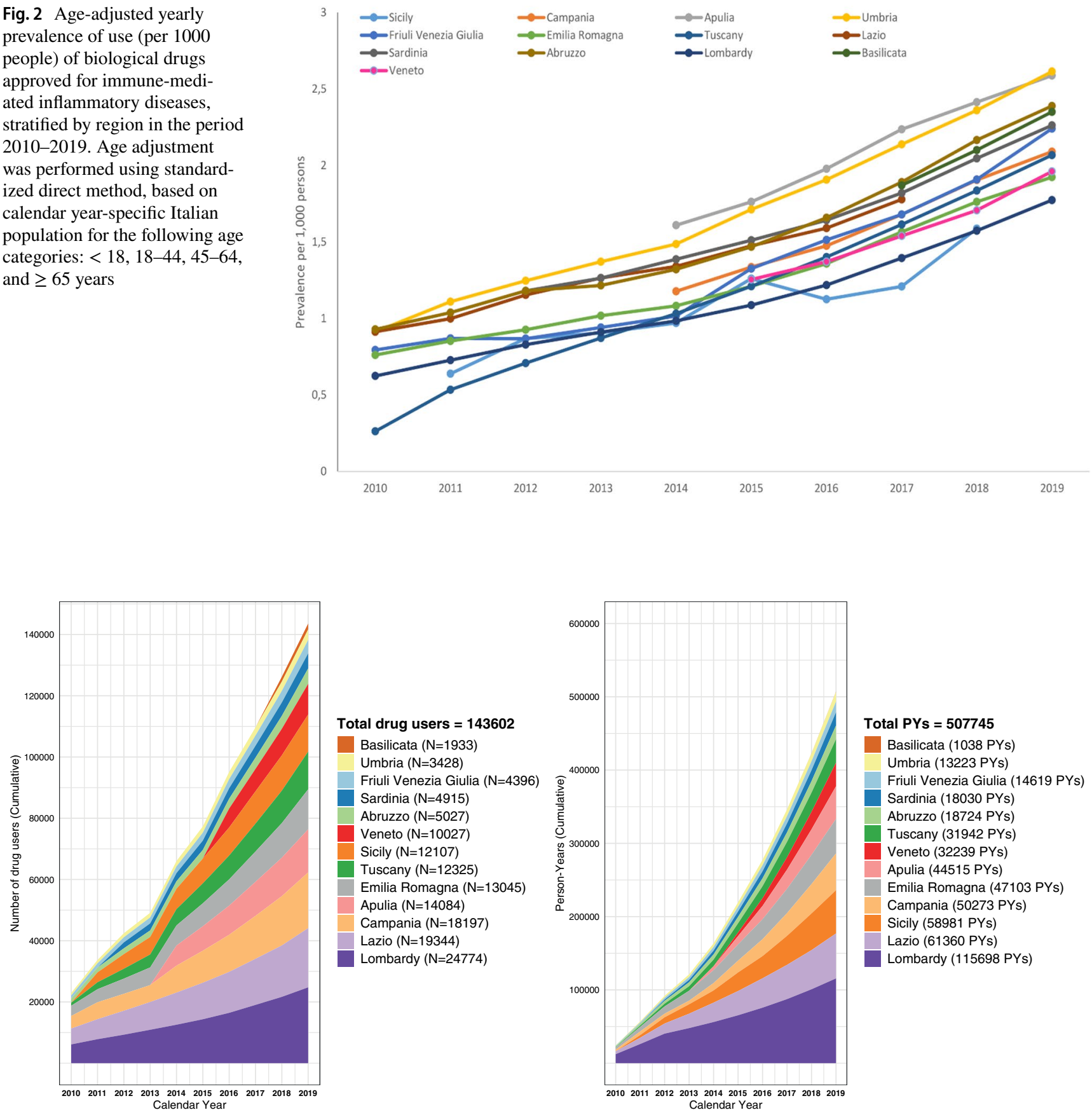

Fig. 3 Cumulated number of biological drug users (left) and person-years (PYs) of biological drug exposure (right) during the study period 2010-2019, stratified by regions 
of claims data for almost 95 million patients in the USA. In Europe (especially Northern Europe), a number of well consolidated disease registries, such as DANBIO, were also set up for postmarketing surveillance of biological drugs in IMIDs; they include electronic data of treatments with biological drugs collected during periodic visits by specialists or other healthcare professionals (e.g., nurses) and clinical information recorded by patients [19]. In comparison, the VALORE project network collects all routinely provided healthcare services provided to biological drug users using several claims databases, which can be further supplemented with clinical data from linkable regional disease registries, whenever available.

The yearly prevalence of biological drug users increased overall on average from 0.7 per 1000 in 2010 to 2.1 per 1000 in 2019 . Heterogeneity across regions has been documented. The availability of highly qualified specialist centers, regional drug policies, and characteristics of underlying population may all account for differences in biological drug access across geographic areas.

Several biological drug utilization studies from other European countries have been previously published. Fassmer et al. [33] investigated the frequency of biological drug use in a cross-sectional study, based on the claims data of a large German health insurance database. Consistent with our results, although the study period was older, the prevalence of biological drug use increased steadily from 2004 to 2011 (from 0.35 per 1000 inhabitants in 2004 to 1.54 per 1000 inhabitants in 2011) [33].

The VALORE project network currently covers 143,602 individual biological drug users and a cumulative 507,745 PYs of exposure. As compared with 2010, the total number of biological drug users was fourfold larger in $2019(N=$ $92,744)$, in line with the increased use of several biological drugs over the years reported by the national reports on medicine use in Italy [34-37] and with the results from the previously described population-based study conducted in Germany [33]. Similarly, Mendelsohn et al. [38] evaluated the incident use of biologic anti-inflammatory agents in BBCIC's distributed research from 2012 to 2019. They identified 160,866 (0.5\%) incident users of TNF $\alpha$ inhibitors, abatacept, anakinra, brodalumab, canakinumab, and guselkumab [38]. The increasing trend in the yearly prevalence of use of biological drugs across all the regions during the study years could be related to multiple factors, such as the marketing of several biological drugs (e.g., secukinumab, vedolizumab), including biosimilars, in more recent years as well as the extensions of the approved indications for use for many frequently prescribed biological drugs (e.g., adalimumab), thus expanding the number of patients eligible for the biological treatments.

The large-scale population of biological drug users collected from VALORE project networks is essential to investigate the association between several clinically relevant
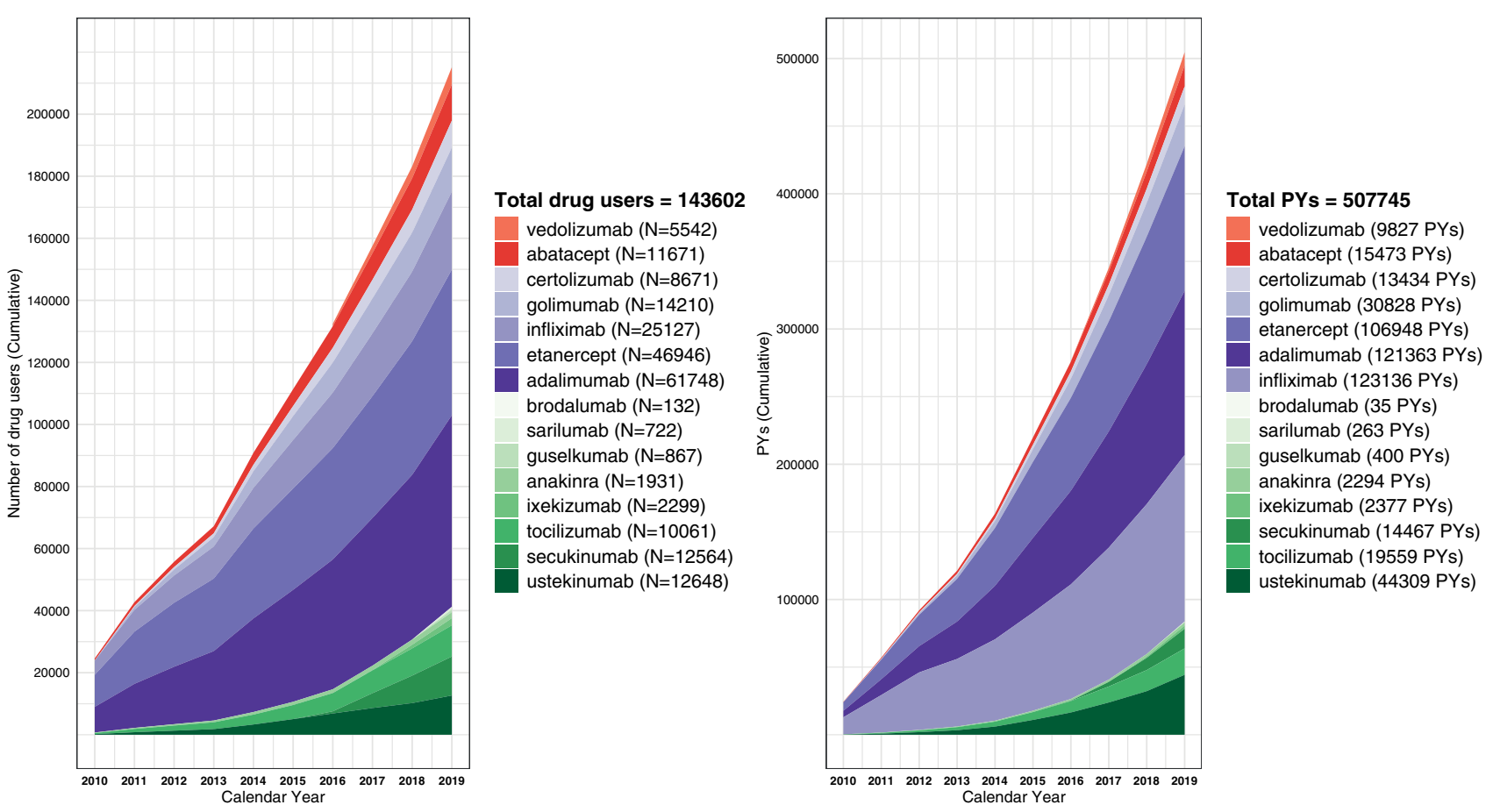

Fig. 4 Cumulated number of biological drug users (left) and person-years (PYs) of biological drug exposure (right) during the study period 2010-2019, stratified by single molecule 
A

INFLIXIMAB

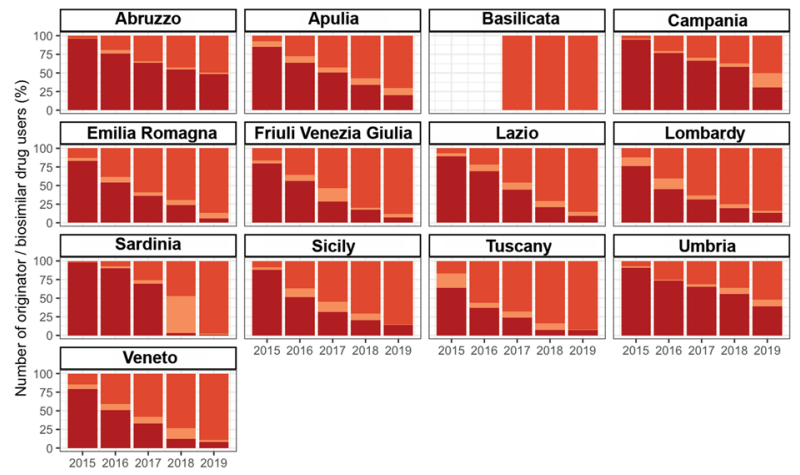

B

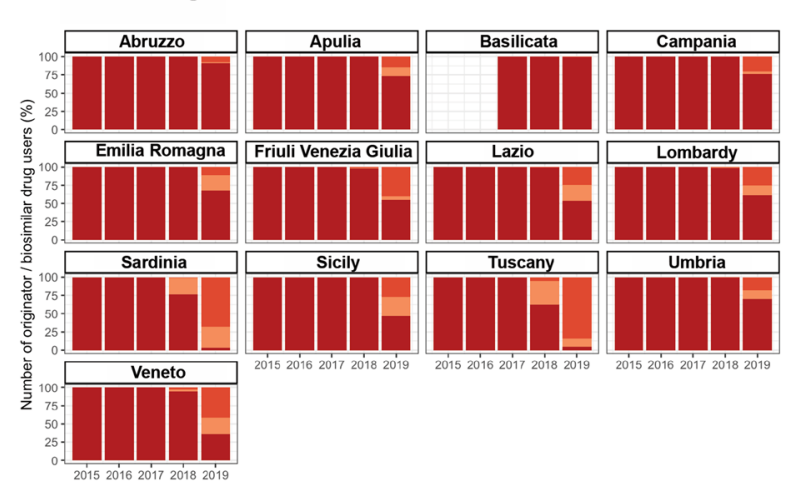

C

ETANERCEPT

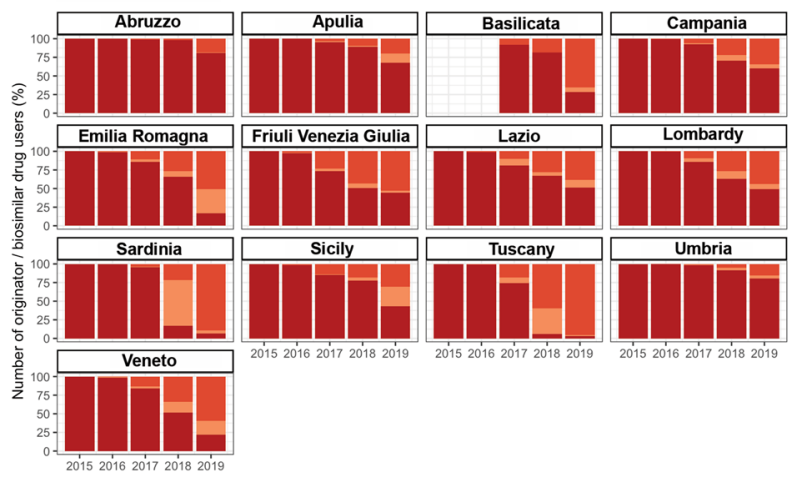

D

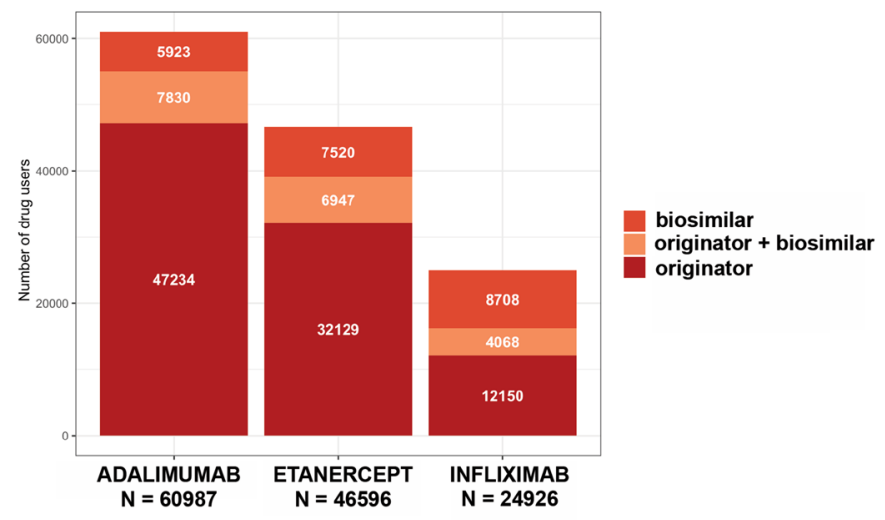

Biosimilar users: one or more dispensing of biosimilar only; originator users: one or more dispensing of originator only; originator + biosimilar users: one or more dispensing of biosimilar and one or more dispensing of originator outcomes and individual biological drugs, as pivotal trials of marketed biological drugs generally recruited too few patients for accurate investigation of the safety profiles of those drugs. For example, the pivotal PHOENIX 1 and 2 clinical trials of ustekinumab included slightly more than 700 and around 1200 patients with psoriasis, respectively, whereas pivotal phase III clinical trials of adalimumab treated 1368 patients overall $[39,40]$.

With regard to drug classes, we observed a progressively increasing use of interleukin inhibitors, especially in the last 4 observation years (2016-2019), with more than 40,000 users overall captured by the network in these years. Very low numbers of users were identified only for brodalumab, sarilumab, and guselkumab, since these drugs were introduced to the market at the end of the observation period; in some regions, market access of those biological drugs was further delayed because of the evaluation procedure for inclusion into the regional drug formulary, thus generating possible inequality in quality of care across Italian regions [41].

TNF $\alpha$ inhibitors were the most frequently dispensed biological drugs (395,709 PYs of exposure related to 118,276 biological drug users), which is due to the observation period under study. As compared with chemically synthetized small molecules, more uncertainties about the safety of biological drugs at the time of approval may exist [42]. Considering that clinical trials are not able to detect rare adverse outcomes or those with a long latency, the safety profiles of biological drugs should always be intensively monitored in the real-world setting.

Using data from eight European healthcare databases, a previous large-scale retrospective study estimated the number of drugs (not restricted to biological drugs) that could be monitored for surveillance of a range of safety outcomes with different background IRs (acute myocardial infarction, upper gastrointestinal bleeding, acute renal failure, 


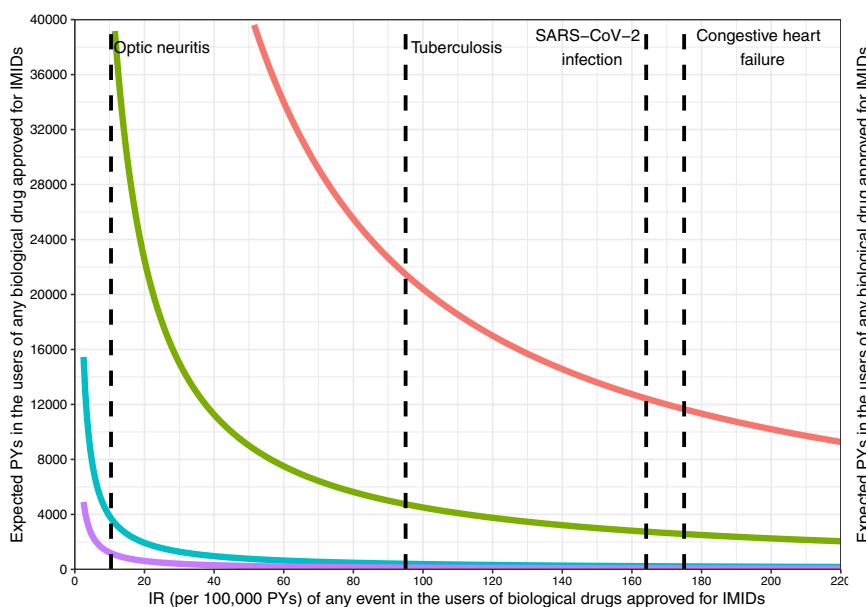

Incidence Rate Ratio $-1.5=2=4 \div 6$

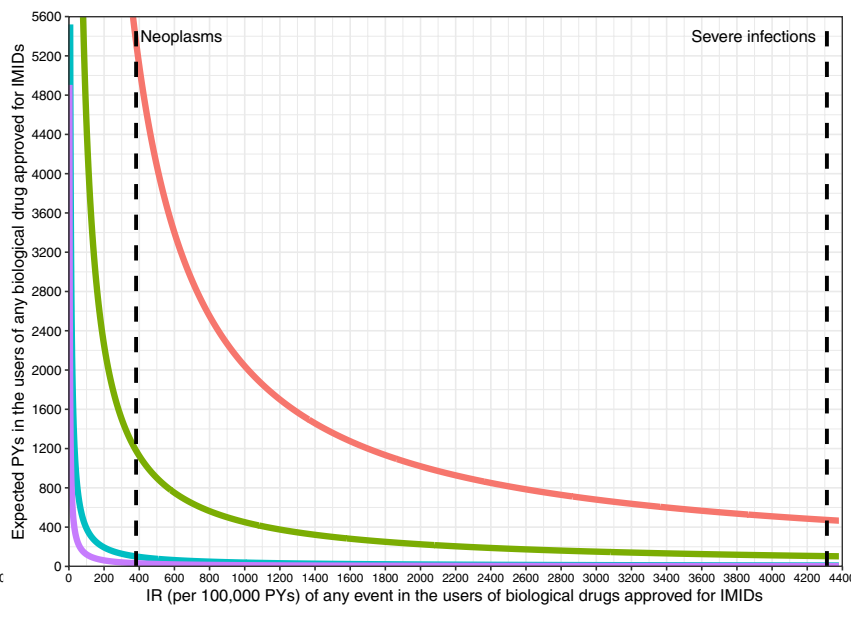

ered based on scientific literature: 175 for 100,000 PYs for congestive heart failure, 95 for 100,000 PYs for tuberculosis, 10.4 for 100,000 PYs for optic neuritis, 382 for 100,000 PYs for neoplasms, 164.1 for 100,000 PYs for SARS-CoV-2 infection, 4312 for 100,000 PYs for severe infections. $I M I D$ immune-mediated inflammatory diseases, $I R$ incidence rate, $P Y S$ person-years, $S A R S-C o V-2$ severe acute respiratory syndrome coronavirus 2
Fig. 7 Minimum detectable relative risk for important pregnancy-related adverse events associated to biological drug users in pregnant women

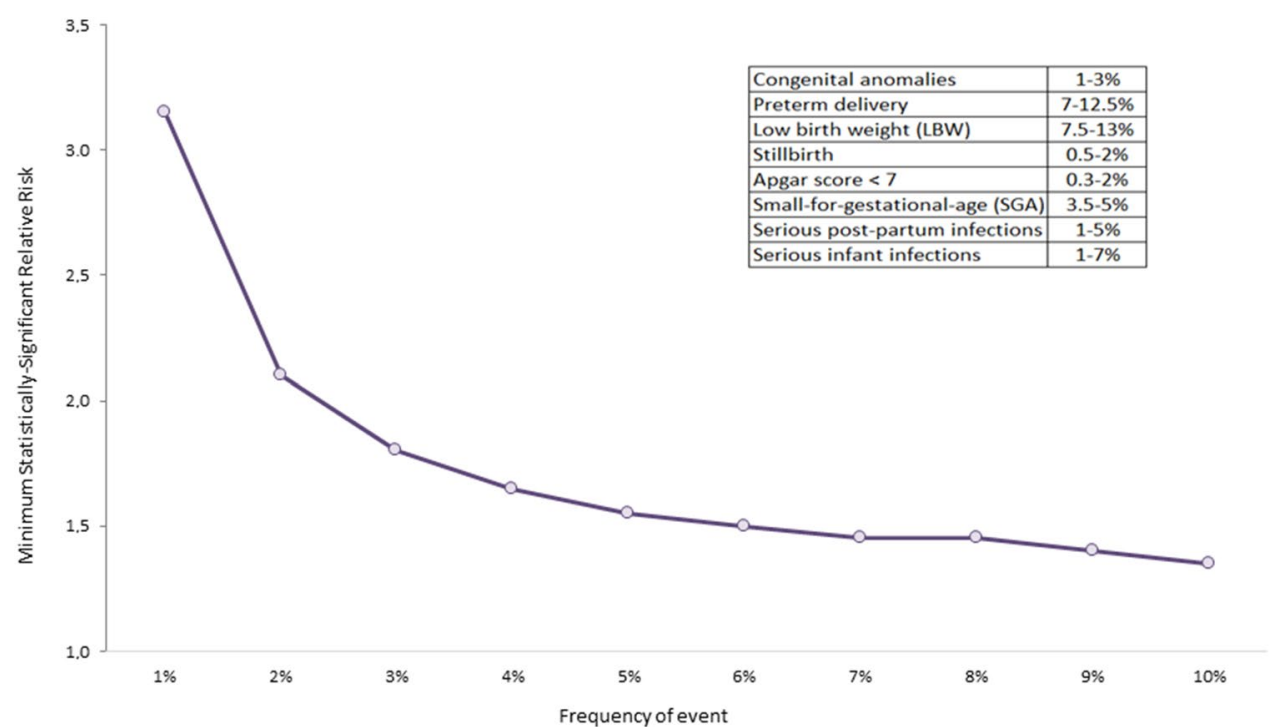

biological drugs and drug classes, the gained statistical power of this network may enable comparative safety studies to be conducted for almost all individual IMID-approved biological drugs.

The number of PYs of exposure (12,439 PYs) to any biological drugs approved for IMIDs that would be necessary to detect a weak association (IR 1.5) with SARS-CoV-2 infection was also identified. The SARS-CoV-2 pandemic also raised concerns about the management of patients with IMIDs. In general, the relationship between the risk of SARS-COV-2 infection/COVID-19 prognosis and use of IMID-approved biological drugs remains under debate $[8$, 
9]. Although it has been reported that use of TNF $\alpha$ inhibitors and interleukin-12/23 inhibitors in patients with inflammatory bowel disease or psoriasis did not worsen the clinical course of COVID-19 [45, 46], data are still too scarce to allow firm conclusions about associations between individual biological compounds and COVID-19. Through the linkage of COVID-19 regional registries and claims data, the VALORE project distributed database network may properly investigate this important safety outcome in large cohorts of biological drug users. This approach has already been adopted to investigate the relationship between COVID-19 prognosis and angiotensin-converting enzyme inhibitors/ angiotensin receptor blockers or hydroxychloroquine/chloroquine and other conventional disease-modifying antirheumatic drugs in rheumatic patients and to measure the survival rate of hospitalized patients with COVID-19 [14, 26, 27]. Another aspect of interest concerns the use of biosimilars. International regulatory authorities have taken different positions about the interchangeability of originator and biosimilars $[16,21]$. In the VALORE project network, we captured data on 40,996 users of biosimilars of infliximab, adalimumab, and etanercept during the years 2015-2019. The use of those biosimilars has increased significantly over recent years, albeit with heterogeneity across Italian regions, as documented in the national reports on medicine use in Italy [34-37] and previous Italian real-world studies [47, 48]. This finding is probably due to the implementation of different regional health policies for promoting biosimilar use [49].

Interestingly, $46 \%$ of etanercept, adalimumab, and infliximab biosimilar users switched between originator and biosimilars (or vice versa) during the follow-up, thus highlighting the potential of such a database network in the investigation of the interchangeability of originators and biosimilars in real-world settings. As it is unrealistic for randomized controlled trials to be systematically carried out to explore all potential switches of originator and related multiple biosimilars, intensified postmarketing surveillance, in addition to evidence of biosimilarity, has been suggested as an optimal approach for ensuring the interchangeability of biosimilars and originators [15].

\subsection{Strengths and Limitations}

The main strength of this population-based study was the large size of the data source and the almost nationwide coverage (almost 50 million Italian people over a total population of more than 60 million) for a period of 10 years, which can be further extended with the continuous accrual of more recent data and possibly other regions. The VALORE project network captured data from 13 Italian regions, including almost all the most densely populated areas (e.g., Lombardy, Campania, Lazio, Sicily, and Veneto regions). The underlying population from 13 Italian regions included in the VALORE project network registered a mean age ranging from 42.1 to 47.1 years, with an $F / M$ ratio of 1.1, in line with the mean age (range 43.3-48.5 years) and sex distribution ( $\mathrm{F} / \mathrm{M}$ ratio 1.1) observed in the underlying population of the other eight Italian regions as proof of the representativeness of the population of VALORE project network [23]. As onethird of biological drugs approved for IMIDs were marketed in Italy before 2016, use of the VALORE project database network for the long-term assessment of patterns of use and the comparative safety and effectiveness of different biological drugs, including biosimilars, is feasible.

Since our study focused on 13 Italian regions from northern, central, and southern Italy, and the trends of biological drug users over the years from these databases were consistent with those documented in Italian national reports on drug consumption, our findings may be considered representative of the whole Italian population.

Moreover, this study reported data for specific subgroups of biological drug users, such as pregnant women, for whom information from pivotal studies of biological drugs is lacking.

The open-source R-based tool (TheShinISS), developed for distributed analyses within a CDM framework, not only enabled us to involve a large and growing number of regions but also, once customized, provided the opportunity to rapidly update the data and analytical dataset, in line with data privacy regulations.

Some limitations of the study warrant caution. First, we did not perform analysis stratified by indication of use, which may be more informative. As some regions also provide access to electronic therapeutic plans completed by specialists for prescribing biological drugs and including information on exact indication for use, validation studies of coding algorithms for identifying the main indication of use of biological drugs approved for IMIDs are ongoing. As regards the power calculation specifically, which is irrespective of indications of use, it should be noted that the risk of safety outcomes may vary across different indications of use; on the other hand, all the indications approved for the biological drugs under investigation are inflammatory and immune-mediated diseases. As such, it is unlikely that differences in risk (if any) of safety outcomes across various indications of use are substantial [50]; as such, the risk assessment of safety outcomes associated with biological drugs approved for IMIDs is likely to be informative even if not stratified by indication of use.

Second, the databases may not have captured all study drug dispensing (e.g., biological drugs occasionally administered to inpatients during a hospitalization). However, it is unlikely that this limitation influenced the study results. Moreover, some biological drugs, such as tildrakizumab, risankizumab, and brodalumab, have only been fully 
reimbursed by the Italian national health system since 2019, yielding a very low number (or null in some regions) of users, which, at the moment, prevents any postmarketing assessment.

Third, the estimated power of the network may be reduced for safety outcomes assessment, when restricted to specific indications or patient categories (e.g., children, very old patients, pregnant women); however, the network currently cumulates such a large number of biological drug users that analyses on major safety outcomes for the most frequently prescribed individual compounds will be possible.

Fourth, exposure to biological drugs was assessed on the basis of DDD, but situations in which some patients intensify/reduce the dose regimen could clearly occur, so DDD could not reflect the exact doses actually used in clinical practice. However, this approach has been commonly used as one of the most accurate ways to estimate dosing regimens using claims databases in pharmacoepidemiology, and it is unlikely to substantially influence our results.

Fifth, concerning interchangeability between reference biological products and biosimilars, the most accurate approach to investigating the potentially related immunogenicity is testing levels of antidrug antibodies. However, it is known that antidrug antibodies are not measured routinely in clinical practice, and even if measured, generally claims databases rarely capture information on laboratory findings. Nevertheless, the VALORE project claims database network may potentially explore safety outcomes related to immunogenicity in cases of clinical manifestation, such as serious hypersensitivity reactions leading to hospitalization or emergency department visits, or lack of effectiveness, which may be measured using some composite outcomes as proxy, as done in previous claims database studies on biological drugs [51].

Sixth, safety outcomes (especially those with a long latency period, e.g., neoplasms) observed during follow-up could not be associated with the biological drug dispensed at ID but could also be associated with a biological drug other than the index drug/small molecule after a switch; therefore, a proper methodological approach would be required.

Finally, clinically relevant information about IMIDs (e.g., disease severity) was missing from the network of regional claims databases. Nevertheless, one of the ambitious goals of the VALORE project is to enrich claims data with clinically relevant information such as disease activity scores, exact indication of use, and reasons for treatment discontinuation through linkage with population-based disease registries from the same catchment area, which are available in some Italian regions [52-54]. For this scope, exploratory analyses have been conducted in the last year to link regional claims data with the Sicilian registry of biological drug users with inflammatory bowel disease and will be conducted in the near future with Veneto registries of biological drugs users with dermatology, rheumatology, or gastroenterology diseases.

\section{Conclusions}

During the period 2010-2019, the VALORE project multidatabase network identified 143,602 biological drug users from 13 Italian regions. The statistical power of this largescale distributed database network allowed the postmarketing surveillance of individual biological drugs with respect to a broad range of clinically relevant safety outcomes, including SARS-CoV-2 infection. The VALORE project multi-database network can be further powered by adding data from more recent calendar years of follow-up and from other regions and can be enriched through linkage with population-based clinical registries. Such a network has great potential to generate real-world evidence on comparative benefit-risk assessments of individual biological drugs in patients with autoimmune diseases as well as on the interchangeability of originators and related biosimilars.

Supplementary Information The online version contains supplementary material available at https://doi.org/10.1007/s40259-021-00498-3.

Acknowledgments VALORE Project Collaborators: VALORE project coordinator group: Gianluca Trifirò, Ugo Moretti, Riccardo Lora, Alberto Sabaini, Valentina Isgrò, Ylenia Ingrasciotta, Valentina Ientile, Luca L'Abbate, Saveria Serena Foti, Stefania Spila Alegiani, Valeria Belleudi, Francesca Poggi, Andrea Fontana, Marco Massari, Ilaria Andretta, Matilde Tanaglia; Abruzzo: Ilenia Senesi, Carla Sorrentino; Basilicata: Maria Rosalia Puzo, Angela Padula, Antonio Carriero, Sergio Sassano; Calabria: Giovambattista De Sarro, Simona Mirarchi, Caterina Palleria, Caterina De Sarro; Campania: Mariano Fusco, Roberta Giordana, Marianna Balestrieri, Stefania Rostan, Annalisa Capuano, Francesca Futura Bernardi, Ugo Trama, Alessandro Russo, Maria Grazia Fumo; Lazio: Valeria Belleudi, Francesca Poggi, Antonio Addis, Felice Musicco; Emilia Romagna: Valentina Solfrini, Ester Sapigni, Aurora Puccini, Ilaria Mazzetti, Debora Podetti, Anna Maria Potenza, Victoria Nikitina, Rita Ricciardelli, Nazanin Mogheiseh, Silvia Croce; Friuli Venezia Giulia: Paola Rossi, Aba Pettinelli, Stefania Del Zotto, Lucian Ejlli; Lombardia: Olivia Leoni, Ida Fortino, Michele Ercolanoni, Arianna Mazzone, Andrea Nisic, Simone Schiatti, Monica Ludergnani, Martina Zanforlini; Marche: Mauro Mancini, Luigi Patregnani, Paolo Fabbietti, Elisa Antonicelli, Antea Mangano; Provincia Autonoma di Trento: Annalisa Campomori, Silvana Annamaria Urru, Giorgio Costa, Giovanni M. Guarrera; Puglia: Domenica Ancona, Vito Bavaro, Paolo Stella; Sardegna: Donatella Garau, Enrico Serra, Stefano Ledda, Paolo Carta; Sicilia: Salvatore Scondotto, Alessandra Allotta; Toscana: Rosa Gini, Marco Tuccori, Alfredo Vannacci, Ersilia Lucenteforte, Maria Parrilli, Irma Convertino; Umbria: Giampaolo Bucaneve, Marcello De Giorgi, David Franchini, Rosalba Elisabetta Rocchi, Mariangela Rossi; Veneto: Giovanna Scroccaro, Anna Cavazzana, Valeria Biasi, Paola Deambrosis, Giampietro Grindelli, Eliana Ferroni.

Funding Open access funding provided by Università degli Studi di Verona within the CRUI-CARE Agreement. 


\section{Declarations}

Funding This study was funded by the Italian Medicines Agency in the context of the multiregional pharmacovigilance project (AIFA 2012-2014: Postmarketing evaluation of the benefit-risk profile of originator biological drugs and biosimilars in the dermatological, rheumatological, gastroenterological and onco-hematological areas through the establishment of a single multiregional network for the integrated analysis of data from health databases, active surveillance and clinical registers; VALORE project).

Conflict of interest In the last 3 years, Gianluca Trifirò has served on advisory boards/seminars funded by several pharmaceutical companies marketing biologics originators and biosimilars on topics unrelated to this paper; he was the scientific director of a Master program on pharmacovigilance, pharmacoepidemiology, and real-world evidence at University of Messina, which received non-conditional grants from various pharmaceutical companies; he coordinated a pharmacoepidemiology team at the University of Messina until October 2020, which received funding for conducting observational studies from various pharmaceutical companies; he is also scientific coordinator of the academic spin-off "INSPIRE srl," which received funding for conducting observational studies from contract research organizations (RTI Health Solutions, Pharmo Institute N.V.), based on funding from pharmaceutical companies. None of these listed activities are related to the topic of the manuscript. Ylenia Ingrasciotta is the CEO of the academic spinoff "INSPIRE srl" of the University of Messina, which has received funding for conducting observational studies from contract research organizations (RTI Health Solutions, Pharmo Institute N.V.). Rosa Gini is the head of the Pharmacepidemiology Unit of ARS Toscana. The budget of her unit is partially supported by contracts with pharmaceutical companies whose products are studied in the VALORE project. Such studies are compliant with the ENCePP Code of Conduct. Valentina Isgrò, Valentina Ientile, Luca L'Abbate, Saveria Serena Foti, Valeria Belleudi, Francesca Poggi, Andrea Fontana, Ugo Moretti, Riccardo Lora, Alberto Sabaini, Ilenia Senesi, Carla Sorrentino, Maria Rosalia Puzo, Angela Padula, Mariano Fusco, Roberta Giordana, Valentina Solfrini, Aurora Puccini, Paola Rossi, Stefania Del Zotto, Olivia Leoni, Martina Zanforlini, Domenica Ancona, Vito Bavaro, Donatella Garau, Stefano Ledda, Salvatore Scondotto, Alessandra Allotta, Marco Tuccori, Giampaolo Bucaneve, David Franchini, Anna Cavazzana, Valeria Biasi, Stefania Spila Alegiani, and Marco Massari have no conflicts of interest that are directly relevant to the content of this article.

Ethics approvals This study was conducted in the context of the multiregional active pharmacovigilance VALORE project, funded by the Italian Medicines Agency. This retrospective study protocol was notified to the Ethical Committee of the Academic Hospital of Messina, which was the project's coordinating center at the time of protocol submission, according to the current national law. The manuscript does not contain clinical studies or patient data. Formal consent is not required for this type of study.

Consent Not applicable

Availability of data and material The datasets generated and/or analyzed during the current study are not publicly available because of privacy reasons.

\section{Code availability Not applicable}

Author contributions Gianluca Trifirò and Marco Massari conceived the study. Acquisition of data: Ilenia Senesi, Carla Sorrentino (Abruzzo), Maria Rosalia Puzo, Angela Padula (Basilicata), Mariano Fusco, Roberta Giordana (Campania), Valentina Solfrini, Aurora Puccini
(Emilia-Romagna), Paola Rossi, Stefania Del Zotto (Friuli Venezia Giulia), Valeria Belleudi, Francesca Poggi (Lazio), Olivia Leoni, Martina Zanforlini (Lombardia), Domenica Ancona, Vito Bavaro (Puglia), Donatella Garau, Stefano Ledda (Sardegna), Salvatore Scondotto, Alessandra Allotta (Sicilia), Marco Tuccori, Rosa Gini (Toscana), Giampaolo Bucaneve, David Franchini (Umbria), Anna Cavazzana, Valeria Biasi (Veneto). Data management: Valentina Ientile, Luca L'Abbate, Saveria Serena Foti, Stefania Spila Alegiani, Valeria Belleudi, Francesca Poggi, Andrea Fontana, Marco Massari. Analysis and interpretation of data: Gianluca Trifirò, Ugo Moretti, Riccardo Lora, Alberto Sabaini, Valentina Isgrò, Ylenia Ingrasciotta, Valentina Ientile, Luca L'Abbate, Saveria Serena Foti, Stefania Spila Alegiani, Valeria Belleudi, Francesca Poggi, Andrea Fontana, Marco Massari. Preparation of manuscript: Valentina Isgrò, Ylenia Ingrasciotta. Gianluca Trifirò critically revised the paper.

Open Access This article is licensed under a Creative Commons Attribution-NonCommercial 4.0 International License, which permits any non-commercial use, sharing, adaptation, distribution and reproduction in any medium or format, as long as you give appropriate credit to the original author(s) and the source, provide a link to the Creative Commons licence, and indicate if changes were made. The images or other third party material in this article are included in the article's Creative Commons licence, unless indicated otherwise in a credit line to the material. If material is not included in the article's Creative Commons licence and your intended use is not permitted by statutory regulation or exceeds the permitted use, you will need to obtain permission directly from the copyright holder. To view a copy of this licence, visit http://creativecommons.org/licenses/by-nc/4.0/.

\section{References}

1. European Medicines Agency. Committee for Medicinal Products for Human Use (CHMP): guideline on similar biological medicinal products containing biotechnology-derived proteins as active substance: non-clinical and clinical issues. https://www. ema.europa.eu/en/documents/scientific-guideline/guideline-simil ar-biological-medicinal-products-containing-monoclonal-antib odies-non-clinical_en.pdf. Accessed 8 Mar 2021.

2. Cutroneo PM, Isgrò V, Russo A, Ientile V, Sottosanti L, Pimpinella G, Conforti A, Moretti U, Caputi AP, Trifirò G. Safety profile of biological medicines as compared with non-biologicals: an analysis of the Italian spontaneous reporting system database. Drug Saf. 2014;37(11):961-70. https://doi.org/10.1007/s40264014-0224-1 (PMID: 25255847).

3. Sharma B. Immunogenicity of therapeutic proteins. Part 3: impact of manufacturing changes. Biotechnol Adv. 2007;25(3):325-31. https://doi.org/10.1016/j.biotechadv.2007.01.007 (Epub 2007 Jan 30. PMID: 17337334).

4. Giezen TJ, Mantel-Teeuwisse AK, Leufkens HG. Pharmacovigilance of biopharmaceuticals: challenges remain. Drug Saf. 2009;32(10):811-7. https://doi.org/10.2165/11316550-00000 0000-00000 (PMID: 19722725).

5. Downing NS, Shah ND, Aminawung JA, Pease AM, Zeitoun JD, Krumholz HM, Ross JS. Postmarket safety events among novel therapeutics approved by the US Food and Drug Administration Between 2001 and 2010. JAMA. 2017;317(18):1854-63. https:// doi.org/10.1001/jama.2017.5150.PMID:28492899;PMCID: PMC5815036.

6. Burke KE, Kochar B, Allegretti JR, Winter RW, Lochhead P, Khalili H, Colizzo FP, Hamilton MJ, Chan WW, Ananthakrishnan AN. Immunosuppressive therapy and risk of COVID-19 infection in patients with inflammatory bowel diseases. Inflamm Bowel Dis. 
2021;27(2):155-61. https://doi.org/10.1093/ibd/izaa278 (PMID: 33089863;PMCID:PMC7665507).

7. Damiani G, Pacifico A, Bragazzi NL, Malagoli P. Biologics increase the risk of SARS-CoV-2 infection and hospitalization, but not ICU admission and death: real-life data from a large cohort during red-zone declaration. Dermatol Ther. 2020;33(5):e13475. https://doi.org/10.1111/dth.13475 (Epub 2020 May 19. PMID: 32356577; PMCID: PMC7261990).

8. Lebwohl M, Rivera-Oyola R, Murrell DF. Should biologics for psoriasis be interrupted in the era of COVID-19? J Am Acad Dermatol. 2020;82(5):1217-8. https://doi.org/10.1016/j.jaad. 2020.03.031 (Epub 2020 Mar 19. PMID: 32199889; PMCID: PMC7156810).

9. Bashyam AM, Feldman SR. Should patients stop their biologic treatment during the COVID-19 pandemic. J Dermatolog Treat. 2020;31(4):317-8. https://doi.org/10.1080/09546634.2020.17424 38 (Epub 2020 Mar 19 PMID: 32191143)

10. Mikuls TR, Johnson SR, Fraenkel L, Arasaratnam RJ, Baden LR, Bermas BL, Chatham W, Cohen S, Costenbader K, Gravallese EM, Kalil AC, Weinblatt ME, Winthrop K, Mudano AS, Turner A, Saag KG. American College of Rheumatology guidance for the management of rheumatic disease in adult patients during the COVID-19 pandemic: version 3. Arthritis Rheumatol. 2021;73(2):e1-12. https://doi.org/10.1002/art.41596 (Epub 2020 Dec 5 PMID: 33277981).

11. Crisafulli S, Isgrò V, La Corte L, Atzeni F, Trifirò G. Potential role of anti-interleukin (IL)-6 drugs in the treatment of COVID-19: rationale. Clinical Evidence and Risks BioDrugs. 2020;34(4):415-22. https://doi.org/10.1007/s40259-020-004301 (PMID:32557214;PMCID:PMC7299248).

12. Sultana J, Crisafulli S, Gabbay F, Lynn E, Shakir S, Trifirò G. Challenges for drug repurposing in the COVID-19 pandemic era. Front Pharmacol. 2020;6(11): 588654. https://doi.org/10.3389/ fphar.2020.588654 (PMID:33240091;PMCID:PMC7677570).

13. Convertino I, Tuccori M, Ferraro S, Valdiserra G, Cappello E, Focosi D, Blandizzi C. Exploring pharmacological approaches for managing cytokine storm associated with pneumonia and acute respiratory distress syndrome in COVID-19 patients. Crit Care. 2020;24(1):331. https://doi.org/10.1186/s13054-020-03020-3 (PMID:32527304;PMCID:PMC7289228).

14. Trifirò G, Massari M, Da Cas R, Menniti Ippolito F, Sultana J, Crisafulli S, Giorgi Rossi P, Marino M, Zorzi M, Bovo E, Leoni O, Ludergnani M, Spila AS, ITA-COVID-19: RAAS inhibitor group. Renin-angiotensin-aldosterone system inhibitors and risk of death in patients hospitalised with COVID-19: a retrospective Italian Cohort Study of 43,000 Patients. Drug Saf. 2020;43(12):1297308. https://doi.org/10.1007/s40264-020-00994-5.

15. Kurki P, van Aerts L, Wolff-Holz E, Giezen T, Skibeli V, Weise M. Interchangeability of biosimilars: a European Perspective. BioDrugs. 2017;31(2):83-91. https://doi.org/10.1007/s40259017-0210-0 (PMID: 28120313).

16. Trifirò G, Marcianò I, Ingrasciotta Y. Interchangeability of biosimilar and biological reference product: updated regulatory positions and pre- and post-marketing evidence. Expert Opin Biol Ther. 2018;18(3):309-15. https://doi.org/10.1080/14712598.2018. 1410134 (Epub 2017 Nov 29 PMID: 29186988).

17. Elkayam O, Pavelka K. Biologic registries in rheumatology: lessons learned and expectations for the future. Autoimmun Rev. 2012;12(2):329-36. https://doi.org/10.1016/j.autrev.2012.05.009 (Epub 2012 Jun 7 PMID: 22683382).

18. Amin M, Lee EB, Bhutani T, Wu JJ. Review of European registries for psoriasis. J Dermatolog Treat. 2019;30(3):227-36. https://doi.org/10.1080/09546634.2018.1506084 (Epub 2018 Sep 14 PMID: 30051739).
19. Hetland ML. DANBIO: a nationwide registry of biological therapies in Denmark. Clin Exp Rheumatol. 2005;23(5 Suppl 39):S205-7 (PMID: 16273809).

20. Biologics and Biosimilars Collective Intelligence Consortium (BBICI). https://bbcic.org/. Accessed 8 Mar 2021.

21. Ingrasciotta Y, Sultana J, Kirchmayer U, Trifirò G. Challenges in post-marketing studies of biological drugs in the era of biosimilars: a report of the International Society for Pharmacoepidemiology 2019 Mid-Year Meeting in Rome. Italy BioDrugs. 2019;33(4):345-52. https://doi.org/10.1007/s40259-019-00365-2 (PMID: 31313085).

22. Trifirò G, Sultana J, Bate A. From big data to smart data for pharmacovigilance: the role of healthcare databases and other emerging sources. Drug Saf. 2018;41(2):143-9. https://doi.org/10.1007/ s40264-017-0592-4 (PMID: 28840504).

23. Italian statistical institute. Population data. http://dati.istat.it/ Index.aspx?QueryId=18462. Accessed 30 July 2021.

24. Gini R, Sturkenboom MCJ, Sultana J, Cave A, Landi A, Pacurariu A, Roberto G, Schink T, Candore G, Slattery J, Trifirò G. Different strategies to execute multi-database studies for medicines surveillance in real-world setting: a reflection on the European Model. Clin Pharmacol Ther. 2020;108(2):228-35. https://doi. org/10.1002/cpt.1833 (Epub 2020 May 5. PMID: 32243569; PMCID: PMC7484985).

25. Massari M, Spila Alegiani S, Da Cas R, Menniti IF. "The ShinISS": an open-source tool for conducting distributed analyses within pharmacoepidemiological multi-database studies. Boll Epidemiol Naz. 2020;1:39-45.

26. Ferroni E, Giorgi Rossi P, Spila Alegiani S, Trifirò G, Pitter G, Leoni O, Cereda D, Marino M, Pellizzari M, Fabiani M, Riccardo F, Sultana J, Massari M, ITA-COVID Working Group. Survival of hospitalized COVID-19 patients in Northern Italy: a populationbased cohort study by the ITA-COVID-19 Network. Clin Epidemiol. 2020;12:1337-46. https://doi.org/10.2147/CLEP.S271763.

27. Alegiani SS, Crisafulli S, Rossi PG, Mancuso P, Salvarani C, Atzeni F, Gini R, Kirchmayer U, Belleudi V, Kurotschka PK, Leoni $\mathrm{O}$, Ludergnani M, Ferroni E, Baracco $\mathrm{S}$, Massari M, Trifirò G, ITA-COVID-19 Network. Risk of COVID-19 hospitalization and mortality in rheumatic patients treated with hydroxychloroquine or other conventional DMARDs in Italy. Rheumatology (Oxford). 2021. https://doi.org/10.1093/rheumatology/keab348 (Epub ahead of print. PMID: 33856453).

28. Beaumont JJ, Breslow NE. Power considerations in epidemiologic studies of vinyl chloride workers. Am J Epidemiol. 1981;114(5):725-34. https://doi.org/10.1093/oxfordjournals.aje. a113244 (PMID: 7030065).

29. Dixon WG, Hyrich KL, Watson KD, Lunt M, Galloway J, Ustianowski A. Drug-specific risk of tuberculosis in patients with rheumatoid arthritis treated with anti-TNF therapy: results from the British Society for Rheumatology Biologics Register (BSRBR). Ann Rheum Dis. 2010;69(3):522-8. https://doi.org/10.1136/ard. 2009.118935 (Epub 2009 Oct 22. PMID: 19854715; PMCID: PMC2927681).

30. Carmona L, Descalzo MA, Perez-Pampin E, Ruiz-Montesinos D, Erra A, Cobo T, Gómez-Reino JJ, BIOBADASER and EMECAR Groups. All-cause and cause-specific mortality in rheumatoid arthritis are not greater than expected when treated with tumour necrosis factor antagonists. Ann Rheum Dis. 2007;66(7):880-5. https://doi.org/10.1136/ard.2006.067660 (Epub 2007 Feb 26. PMID: 17324968; PMCID: PMC1955107)

31. Khan N, Patel D, Xie D, Lewis J, Trivedi C, Yang YX. Impact of anti-tumor necrosis factor and thiopurine medications on the development of COVID-19 in patients with inflammatory bowel disease: a Nationwide Veterans Administration Cohort Study. Gastroenterology. 2020;159(4):1545-1546.e1. https://doi.org/ 
10.1053/j.gastro.2020.05.065 (PMID: 32479823; PMCID: PMC7258834).

32. Winthrop KL, Chen L, Fraunfelder FW, Ku JH, Varley CD, Suhler E, Hills WL, Gattey D, Baddley JW, Liu L, Grijalva CG, Delzell E, Beukelman T, Patkar NM, Xie F, Herrinton LJ, Fraunfelder FT, Saag KG, Lewis JD, Solomon DH, Curtis JR. Initiation of anti-TNF therapy and the risk of optic neuritis: from the safety assessment of biologic ThERapy (SABER) Study. Am J Ophthalmol. 2013;155(1):183-189.e1. https://doi.org/10.1016/j.ajo. 2012.06.023 (Epub 2012 Sep 8. PMID: 22967869; PMCID: PMC4142597).

33. Fassmer AM, Garbe E, Schmedt N. Frequency and trends of disease-modifying antirheumatic drug (DMARD) use in Germany. Pharmacol Res Perspect. 2016;4(5): e00254. https://doi.org/10. 1002/prp2.254 (PMID:27713825;PMCID:PMC5045940).

34. Agenzia Italiana del Farmaco (AIFA). L'uso dei farmaci in Italia-rapporto OsMed 2016. https://www.aifa.gov.it/documents/ 20142/241052/Rapporto_OsMed_2016_AIFA-acc.pdf/b44a62586a84-4293-0cdb-1d6f7c4be629.

35. Agenzia Italiana del Farmaco (AIFA). L'uso dei farmaci in Italia-rapporto OsMed 2017. http://www.agenziafarmaco.gov.it/ sites/default/files/Rapporto_OsMed_2017_AIFA.pdf.

36. Agenzia Italiana del Farmaco (AIFA). L'uso dei farmaci in Italia-rapporto OsMed 2018. https://www.aifa.gov.it/documents/ 20142/0/Rapporto_OsMed_2018.pdf/c9eb79f9-b791-2759-4a9ee56e1348a976. Accessed 15 May 2021.

37. Agenzia Italiana del Farmaco (AIFA). L'uso dei farmaci in Italia—rapporto OsMed 2019. https://www.aifa.gov.it/documents/ 20142/1205984/rapporto-osmed-2019.pdf/f41e53a4-710a-7f754257-404647d0fe1e. Accessed 15 May 2021.

38. Mendelsohn AB, Nam YH, Marshall J, McDermott CL, Kochar B, Kappelman MD, Brown JS, Lockhart CM. Utilization patterns and characteristics of users of biologic anti-inflammatory agents in a large, US commercially insured population. Pharmacol Res Perspect. 2021;9(1): e00708. https://doi.org/10.1002/prp2.708 (PMID:33372729; PMCID:PMC7771154).

39. European Medicines Agency. Humira EPAR scientific discussion. https://www.ema.europa.eu/en/documents/scientific-discussion/ humira-epar-scientific-discussion_en.pdf. Accessed on 4 July 2021.

40. European Medicines Agency. Stelara EPAR public assessment report. https://www.ema.europa.eu/en/documents/assessmentreport/stelara-epar-public-assessment-report_en.pdf. Accessed on 4 July 2021.

41. Pizzimenti V, Formica D, Sultana J, Lucchesi S, Aiello A, Ientile V, Trifirò G. Access of medicines to the market: three years' experience of Sicily's regional drug formulary. Gazzetta Med Ital Arch Sci Med. 2020;179(5):317-25.

42. Vermeer NS, Duijnhoven RG, Straus SM, Mantel-Teeuwisse AK, Arlett PR, Egberts AC, Leufkens HG, De Bruin ML. Risk management plans as a tool for proactive pharmacovigilance: a cohort study of newly approved drugs in Europe. Clin Pharmacol Ther. 2014;96(6):723-31. https://doi.org/10.1038/clpt.2014.184 (Epub 2014 Sep 15 PMID: 25222619).

43. Coloma PM, Trifirò G, Schuemie MJ, Gini R, Herings R, Hippisley-Cox J, Mazzaglia G, Picelli G, Corrao G, Pedersen L, van der Lei J, Sturkenboom M, EU-ADR Consortium. Electronic healthcare databases for active drug safety surveillance: is there enough leverage? Pharmacoepidemiol Drug Saf. 2012;21(6):611-21. https://doi.org/10.1002/pds.3197.

44. Hammond IW, Gibbs TG, Seifert HA, Rich DS. Database size and power to detect safety signals in pharmacovigilance. Expert Opin
Drug Saf. 2007;6(6):713-21. https://doi.org/10.1517/14740338.6. 6.713 (PMID: 17967160).

45. Piaserico S, Gisondi P, Cazzaniga S, Naldi L. Lack of evidence for an increased risk of severe COVID-19 in psoriasis patients on biologics: a cohort study from Northeast Italy. Am J Clin Dermatol. 2020;21(5):749-51. https://doi.org/10.1007/s40257-020-00552-w. PMID:32812188;PMCID:PMC7433672.

46. Brenner EJ, Ungaro RC, Colombel JF, Kappelman MD. SECUREIBD database public data update. 2020. https://covid ibd.org. Accessed 15 Mar 2021.

47. Marcianò I, Ingrasciotta Y, Giorgianni F, Bolcato J, Chinellato A, Pirolo R, Di Giorgio A, Manna S, Ientile V, Gini R, Santarpia M, Genazzani AA, Uomo I, Pastorello M, Pollina Addario SW, Scondotto S, Cananzi P, Da Cas R, Traversa G, Rossi M, Sottosanti L, Caputi AP, Trifirò G. How did the introduction of biosimilar filgrastim influence the prescribing pattern of granulocyte colonystimulating factors? Results from a multicentre, population-based study, from Five Italian Centres in the Years 2009-2014. BioDrugs. 2016;30(4):295-306. https://doi.org/10.1007/s40259-0160175-4 (PMID: 27138636).

48. Ingrasciotta Y, Giorgianni F, Bolcato J, Chinellato A, Pirolo R, Tari DU, Troncone C, Fontana A, Ientile V, Gini R, Santoro D, Santarpia M, Genazzani A, Uomo I, Pastorello M, Addario WS, Scondotto S, Cananzi P, Caputi AP, Trifirò G. How much are biosimilars used in clinical practice? A retrospective Italian population-based study of erythropoiesis-stimulating agents in the years 2009-2013. BioDrugs. 2015;29(4):275-84. https://doi. org/10.1007/s40259-015-0132-7 (PMID:26169209;PMCID: PMC4561997).

49. Agenzia Italiana del Farmaco (AIFA). Medicinali biosimiari analisi di sicurezza. https://www.aifa.gov.it/documents/20142/0/ 190712_MedBio19.pdf/05b20f88-0202-c0cb-3079-c6c2966e70 06.

50. Kuek A, Hazleman BL, Ostör AJ. Immune-mediated inflammatory diseases (IMIDs) and biologic therapy: a medical revolution. Postgrad Med J. 2007;83(978):251-60. https://doi.org/10.1136/ pgmj.2006.052688.PMID:17403952;PMCID:PMC2600039.

51. Kirchgesner J, Desai RJ, Beaugerie L, Kim SC, Schneeweiss S. Calibrating real-world evidence studies against randomized trials: treatment effectiveness of infliximab in Crohn's disease. Clin Pharmacol Ther. 2021. https://doi.org/10.1002/cpt.2304 (Epub ahead of print. PMID: 340).

52. Viola A, Muscianisi M, Macaluso FS, Ventimiglia M, Cappello M, Privitera AC, Magnano A, Pluchino D, Magrì G, Ferracane C, Mocciaro F, Garufi S, Giuffrida E, Costantino G, Fiocco G, Grova M, Guida L, Alibrandi A, Orlando A, Fries W, "Sicilian Network for Inflammatory Bowel Disease (SN-IBD)." Ustekinumab in Crohn's disease: real-world outcomes from the Sicilian network for inflammatory bowel diseases. JGH Open. 2021;5(3):364-70. https://doi.org/10.1002/jgh3.12502.

53. Naldi L, Cazzaniga S, Di Mercurio M, Grossi E, Addis A, Psocare study centres. Inequalities in access to biological treatments for psoriasis: results from the Italian Psocare registry. Br J Dermatol. 2017;176(5):1331-8. https://doi.org/10.1111/bjd.15234 (Epub 2017 Apr 5. PMID: 27973689).

54. Caporali R, Sarzi-Puttini P, Atzeni F, Gorla R, Filippini M, Marchesoni A, Favalli EG, Bobbio-Pallavicini F, Montecucco C. Switching TNF-alpha antagonists in rheumatoid arthritis: the experience of the LORHEN registry. Autoimmun Rev. 2010;9(6):465-9. https://doi.org/10.1016/j.autrev.2009.12.010 (Epub 2009 Dec 31 PMID: 20044040). 


\section{Authors and Affiliations}

Gianluca Trifirò $^{1}{ }^{10} \cdot$ Valentina Isgrò $^{1} \cdot$ Ylenia Ingrasciotta ${ }^{2} \cdot$ Valentina lentile $^{2} \cdot$ Luca L'Abbate $^{1} \cdot$ Saveria S. Foti $^{3}$. Valeria Belleudi ${ }^{4}$. Francesca Poggi ${ }^{4}$ - Andrea Fontana ${ }^{5} \cdot$ Ugo Moretti $^{1} \cdot$ Riccardo Lora $^{1}$ - Alberto Sabaini ${ }^{6}$. Ilenia Senesi ${ }^{7}$. Carla Sorrentino ${ }^{8}$ - Maria R. Puzo ${ }^{9}$ - Angela Padula ${ }^{10}$. Mariano Fusco ${ }^{11} \cdot$ Roberta Giordana $^{12}$. Valentina Solfrini ${ }^{13}$. Aurora Puccini ${ }^{13}$. Paola Rossi ${ }^{14}$. Stefania Del Zotto ${ }^{15}$. Olivia Leoni ${ }^{16}$. Martina Zanforlini ${ }^{17}$. Domenica Ancona ${ }^{18}$. Vito Bavaro ${ }^{18}$. Donatella Garau ${ }^{19}$. Stefano Ledda ${ }^{20}$. Salvatore Scondotto ${ }^{21}$. Alessandra Allotta ${ }^{21}$. Marco Tuccori ${ }^{22}$. Rosa Gini ${ }^{23}$. Giampaolo Bucaneve ${ }^{24}$. David Franchini ${ }^{25}$. Anna Cavazzana ${ }^{26}$. Valeria Biasi ${ }^{26}$. Stefania Spila Alegiani ${ }^{27} \cdot$ Marco Massari $^{27}$. VALORE Project Collaborators

Gianluca Trifirò gianluca.trifiro@univr.it

1 Department of Diagnostics and Public Health, University of Verona, 37129 Verona, Italy

2 Department of Biomedical and Dental Sciences and Morphofunctional Imaging, University of Messina, Messina, Italy

3 Academic spin-off "INSPIRE, Innovative Solutions for Medical Prediction and Big Data Integration in Real World Setting", Azienda Ospedaliera Universitaria "G. Martino", Messina, Italy

4 Department of Epidemiology, Lazio Regional Health Service, Rome, Italy

5 Unit of Biostatistics, Fondazione IRCCS Casa Sollievo della Sofferenza, San Giovanni Rotondo, Italy

6 Dipartimento di Informatica, Università degli Studi di Verona, Verona, Italy

7 Territorial Assistance Service, ASL Teramo, Abruzzo, Italy

8 Regional Territorial Assistence Service, Abruzzo, Italy

9 Assistance and Pharmaceutical Services Office, Personal Policies Department, Basilicata Region, Potenza, Italy

10 Rheumatology Institute of Lucania (IReL), San Carlo Hospital of Potenza, Via Potito Petrone, 85100 Potenza, Italy

11 Dipartimento delle Attività Farmaceutiche Territoriali e Ospedaliere, Naples 2 Nord LHU, Naples, Italy

12 Regional Healthcare Society (So.Re.Sa), Naples, Italy
13 Territorial Assistance Service, Drug and Medical Device Area, Emilia Romagna Health Department, Bologna, Italy

14 Direzione Centrale Salute Regione Friuli Venezia Giulia, Trieste, Italy

15 Azienda regionale di coordinamento per la salute (ARCS), Udine, Italy

16 Lombardy Regional Centre of Pharmacovigilance, Milan, Italy

17 Azienda Regionale per l'Innovazione e gli Acquisti, S.p.A, Milan, Italy

18 Apulian Regional Health Department, Bari, Italy

19 General Directorate for Health, Sardinia Region, Italy

20 Sardinia Regional Health Department, Cagliari, Italy

21 Epidemiologic Observatory of the Sicily Regional Health Service, Palermo, Italy

22 Unit of Adverse Drug Reaction Monitoring, University Hospital of Pisa, Pisa, Italy

23 Agenzia Regionale di Sanità Toscana, Florence, Italy

24 Umbria Regional Centre of Pharmacovigilance, Perugia, Italy

25 Health ICT Service, Regional Health Authority of Umbria, Perugia, Italy

26 Azienda Zero, Regione Veneto, Italy

27 Pharmacoepidemiology Unit, National Centre for Drug Research and Evaluation, Istituto Superiore di Sanità, Rome, Italy 